\title{
O mercado de bens simbólicos: a viabilidade política e midiática do Templo de Salomão junto aos stakeholders
}

\author{
The market of symbolic goods: a feasibility political and media from Solomon's \\ Temple to the stakeholders
}

\section{El mercado de bienes simbólicos: una viabilidad política y mediática del Templo de Salomón con las partes interesadas}

\author{
Roberto Bazanini ${ }^{1}$ \\ Jorge Miklos ${ }^{2}$ \\ Homero Leoni Bazanini ${ }^{3}$ \\ Gracy Giradelli ${ }^{4}$
}

\section{Resumo}

No mercado de bens simbólicos, os diferentes grupos de stakeholders constituem elementos representativos na comercialização de produtos e serviços religiosos, ambiente no qual, em termos mercadológicos, contemporaneamente, os megatemplos representam a praça por excelência desse empreendimento. Por intermédio de pesquisa exploratória, de natureza qualitativa, o objetivo da pesquisa está em analisar a importância do Templo de Salomão, megatemplo da Igreja Universal do Reino de Deus (IURD), inaugurado em 31 de julho de 2014, como empresa inserida no concorrencial de bens e serviços religiosos para o alcance de vantagem competitiva. Os resultados da pesquisa apontam que a criação de megatemplos pode ser concebida uma situação real de mercado competitivo capaz de influenciar as estruturas das organizações religiosas pela visibilidade política e midiática que proporciona. A contribuição da pesquisa está em discutir a pertinência da aplicabilidade da teoria dos stakeholders no mercado de bens simbólicos da religião por permitir estudar a criação dos megatemplos como estratégia de marketing a partir da perspectiva dos relacionamentos com outros atores situados no mesmo campo social e estabelecer relações entre a lógica capitalista e a doutrina religiosa.

Palavras-chave: Mercado de bens simbólicos. Megatemplos. Stakeholders.

\section{Abstract}

In the market of symbolic goods, different stakeholder groups are representative elements in the

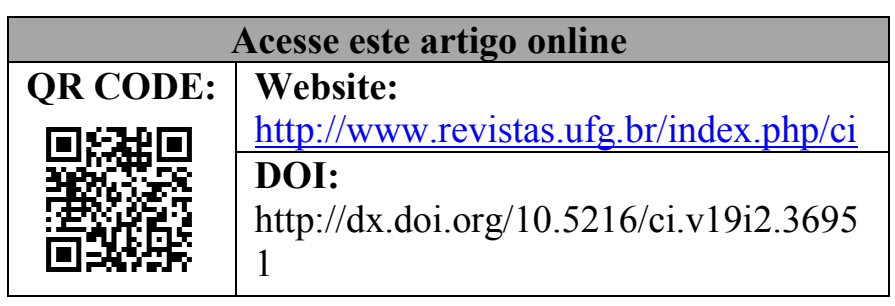
religious market products and services, environment in which, at the market terms, currently, the megachurches represent the place par excellence of this undertaking. According to the exploratory research and qualitative, aim of this the research is to analyze the importance of Solomon's

\footnotetext{
${ }^{1}$ Doutor em Comunicação e Semiótica, Mestre em Comunicação Social e Bacharel em Administração de Empresas, Filosofia e Pedagogia (PUC/SP). Brasil, SP, São Paulo. E-mail: roberto.bazanini@terra.com.br ${ }^{2}$ Doutor em Comunicação e Semiótica e Mestre em Ciência da Religião (PUC/SP). Brasil, SP, São Paulo. Email: jmiklos@bol.com.br

${ }^{3}$ Doutorando em Comunicação Social (UNIP/SP). Brasil, SP, São Paulo. E-mail: homerolaeb@uol.com.br

${ }^{4}$ Graduanda em Administração de Empresas da (UNIP/SP). Brasil, SP, São Paulo. E-mail:

Ggiraldelli@bol.com.br
}

Comun. \& Inf., Goiânia, GO, v. 19, n. 2, p. 106-126, jul./dez. 2016. 
Temple, mega temple belonging to Universal Church of the Kingdom of God (UCKG), opened on July 31 st,

2014, as a company inserted in the competitive religious goods and services for achieving competitive advantage. The survey results show that the creation of mega-temples can be conceive as a real situation of competitive market able to influence the structures of religious organizations by the political and media visibility it provides. The contribution of this research is to discuss the applicability's relevance of the stakeholders theory in the religious market of symbolic goods by allowing for the creation of megachurches as a marketing strategy from the perspective of relationships with other stakeholders placed in the same social field and establish relationships between the capitalist logic and religious doctrine.

Keywords: Market of symbolic goods. Megachurches. Stakeholders.

\section{Resumen}

En el mercado de bienes simbólicos, los diferentes grupos de partes interesadas son elementos representativos de la comercialización de productos y servicios religiosos, el entorno en el que, en términos de mercado, a la vez, los megatemplos representan a la par cuadrada excelencia de esta empresa. Através de la investigación exploratoria, de naturaleza cualitativa, el objetivo de la investigación es analizar la importancia del Templo de Salomón, megatemplo la Iglesia Universal del Reino de Dios (IURD), inaugurado en 31 de julio 2014, como una empresa inserta en el competitivo bienes y servicios para lograr una ventaja competitiva religiosos. Los resultados de la encuesta muestran que la creación de megatemplos se puede concebir una situación real de mercado competitivo capaz de influir en las estructuras de las organizaciones religiosas por la visibilidad política y los medios de comunicación que proporciona. La contribución de la investigación es analizar la relevancia de la aplicabilidad de la teoría de los interesados en el estudio de mercado de bienes simbólicos de la religión, al permitir la creación de megatemplos como una estrategia de marketing desde la perspectiva de las relaciones con otros actores ubicados en el mismo campo social y establecer relaciones entre la lógica capitalista y la doctrina religiosa.

Palabras clave: Mercado de bienes simbólicos. Megatemplos. Las partes interesadas.

\section{INTRODUÇÃO}

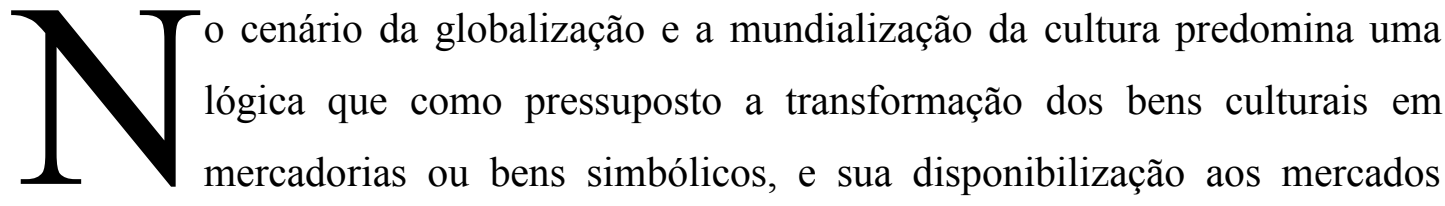

consumidores mundiais através das contínuas inovações tecnológicas presentes nos meios de comunicação.

Decorrente dessas inovações, o emprego dessas novas tecnologias permitiu o crescimento do mercado de bens simbólicos em todos os setores das atividades humanas: religião, entretenimento, desportos, arte, etc., visto que, à medida que estabelecem relações sociais entre si, os homens realizam não somente a troca de mercadorias, mas também de significados, de símbolos, por isso, a existência na sociedade de um mercado de bens simbólicos se torna tão vigoroso quanto o de bens materiais. 
No mercado de bens simbólicos dos desportos, a construção de grandes estádios, como por exemplo, a "Arena Corinthians" em Itaquera e o "Allianz Parque" em Perdizes constituem como monumentos de grandeza e majestade perante a concorrência. Analogamente, no mercado de bens simbólicos da religião, o surgimento dos megatemplos representa o poderio das organizações religiosas num mercado cada vez mais competitivo em decorrência da mercantilização do sagrado.

Decorrentes da mercantilização do sagrado surgiram a indústria da música gospel, as megachurches, os shows-missa, a ritualidade triunfalista dos megatemplos, os megaeventos papais, a obsessão por causar emoção e catarse nos fiéis, o cuidado obsessivo com vestes e decoração, o luxo de terreiros e locais de culto, a teatralidade ensaiada e, sobretudo, a produção “industrial” do próprio espetáculo religioso (MOREIRA, 2015).

Bourdieu e Miceli (1987) concebem a existência de capital religioso que comporta por um lado, os clérigos como produtores de bens simbólicos, por outro, o mercado de leigos ao quais os produtos simbólicos se destinam para serem consumidos.

Contemporaneamente, em termos mercadológicos, na perspectiva da teoria dos quatro Ps (preço, produto, promoção, praça) proposta por McCarthy (1998), a mercantilização do sagrado nos megatemplos representam a praça por excelência desse empreendimento, bastante semelhantes aos supermercados ou shopping centers modernos.

Assim, no mercado de bens simbólicos da religião, a mercantilização do sagrado busca encontrar valores nas coisas, nas atividades e nas pessoas que transcendam meramente o valor econômico e propiciem um sentido de vida que seja muito mais transcendente e profundo do que simplesmente acumular riquezas e ostentar bens de consumo.

O Templo de Salomão, inaugurado em 31 de julho de 2014, com a presença de autoridades, jornalistas, pastores, fiéis e demais stakeholders, demorou mais de quatro anos para ser construído e em termos comparativos é cerca de três vezes maior do que o Santuário Nacional de Aparecida que perde, assim, o posto de maior espaço religioso do país.

O problema da pesquisa está em encontrar respostas para a questão: em que aspectos a construção dos megatemplos proporciona viabilidade política e midiática e consequentemente vantagem competitiva para as organizações religiosas?

Por intermédio de pesquisa exploratória, de natureza qualitativa, tendo como base teórica os adeptos e críticos da vertente Salience Model dos stakeholders, o objetivo da pesquisa está em analisar a importância desse megatemplo da Igreja Universal do Reino de Deus (IURD) como recurso estratégico inserido no concorrencial mercado de bens e serviços 
religiosos e suas especificidades nas formas de comunicação, nos conteúdos religiosos e na sociabilidade dos agentes.

Assim, a presente pesquisa discorre sobre a viabilidade política e midiática do Templo de /Salomão junto aos seus stakeholders no mercado de bens simbólicos.

\section{REVISÃO DA LITERATURA}

Nas últimas três décadas inúmeros trabalhos tem sido publicados sobre o caráter empresarial das organizações religiosas atuantes no mercado de bens simbólicos, dos quais podem-se destacar: Bazanini (1998), Mariano (1999); Oliveira (2002), Miller (2002); Jadon (2009); Magaldi (2009); Miklos (2012), Rocha (2014) e Da Silva Moreira (2015).

Bazanini (1998) discute a disputa mercadológica pelo controle do imaginário popular entre a IURD e a Rede Globo de Televisão. Mariano (1999) afirma que as organizações religiosas não escaparam a lógica do mercado. Oliveira (2002) discorre sobre a profissionalização do pessoal, a captação de recursos financeiros, busca de apoio por parte das empresas e do governo, captação de fiéis. Miller (2002) descreve as estratégias competitivas das organizações religiosas, Jadon (2009) analisa as estratégias persuasivas da Igreja Universal do Reino de Deus numa perspectiva semiótica. Magaldi (2009) esclarece que o entendimento da razão pela qual o ser humano contemporâneo deixou de trocar livremente e passou a acumular, muitas vezes, por meio de consumo do supérfluo, ficando à mercê de um mercado que pretende ser hegemônico, colocando inclusive o dinheiro como caminho de cura e salvação. Miklos (2012) analisa as posturas religiosas presentes no ciberespaço ao discorrer sobre práticas como velas e orações virtuais presentes nos procedimentos mercadológicos para se alcançar futuros fieis potenciais. Rocha (2014) analisa as narrativas dos fieis em dois periódicos da Igreja Mundial do Poder de Deus. Da Silva Moreira (2015) indaga acerca do futuro da religião sob o impacto da cultura da sensação e da inflação do estético e os possíveis potenciais emancipatórios da própria experiência religiosa estetizada e tenta tirar algumas consequências futuras para a religião sob o domínio da estética.

Particularmente em relação à criação de megatemplos, Throup (2011) analisa a utilização simbólica do Templo de Jerusalém, com foco na construção de uma réplica do Templo em São Paulo, caracterizando-a como "misticismo emblemático", no qual o símbolo é esvaziado de seu significado originário e então reconstituído conforme o propósito da organização que o faz; Smith e Campos (2014) discutem criticamente a criação dos megatemplos em termos mercadológicos, Amigo (2014) discorre criticamente como a 
construção do Templo de Salomão pode estar relacionado com o desenvolvimento corrente das religiões e dos espaços religiosos em megacidades atuais. Entretanto, nenhum desses trabalhos aborda a relação entre os megatemplos e os stakeholders envolvidos com os interesses da organização.

A contribuição da pesquisa está em discutir a pertinência da aplicabilidade da teoria dos stakeholders no mercado de bens simbólicos da religião por permitir estudar a criação dos megatemplos como viabilidade política e midiática a partir da perspectiva dos relacionamentos com outros atores situados no mesmo campo social e estabelecer relações entre a lógica capitalista e a doutrina religiosa.

\subsection{OS MEGATEMPLOS}

Comumente, um megatemplo não é apenas avaliado pelas suas dimensões, mas sim pela frequência de pelo menos 2000 participantes numa típica semana de serviço (BIARD, 2006). Em 2011, o missiólogo norte-americano da "Leadership Network” Warren Bird, montou um estudo sobre igrejas com capacidade de megatemplos ao redor do mundo. Constatou que, geralmente os megatemplos são suntuosos, a membresia se comporta como num teatro assistindo um drama que se desenrola com a performance de artistas gospel e líderes carismáticos que se comportam como animadores de auditório.

A relação dos megatemplos elencados pelo missiólogo refere-se apenas às igrejas evangélicas, divididos pelos continentes e recebeu a ajuda via internet de líderes cristãos de todo o mundo e teve como objetivo, retratar a situação dos evangélicos em cada região onde existam esses megatemplos.

É interessante observar que o critério usado por Warren Bird não utiliza apenas dados de capacidade dos templos, mas incorpora também relatos de frequência média dos cultos, tendo em consideração os presentes no culto, inclusive crianças. Na lista foram elencados, Estados Unidos, mais de 1.600 igrejas com capacidade de megatemplos e mais de $1.000 \mathrm{em}$ outras partes do mundo, dos quais, os dez maiores alcançam frequência semanal de pelo menos 45.000 fiéis, conforme tabela 1 . 
Tabela 1 - Os dez maiores megatemplos evangélicos do mundo

\begin{tabular}{|cccc|}
\hline Membros & Nome & Pastor & Localização \\
\hline $230 \mathrm{mil}$ & Yoido Full Gospel & Não Informado & Seul, Coréia do Sul \\
\hline $75 \mathrm{mil}$ & Deep Christian Life Ministry & William Kumuyi & Lagos, Nigéria \\
\hline $60 \mathrm{mil}$ & Faith Church & Sando Nemeth & Budape ste, Hungria \\
\hline $60 \mathrm{mil}$ & Mision Caristmatica Internacional & Cesar Castellanos & Bogotá, Colômbia \\
\hline $60 \mathrm{mil}$ & Pyungkang Cheil & Abraham Park Yoon-Sik & Seul, Coréia do Sul \\
\hline $50 \mathrm{mil}$ & Living Faith & David Oyedepo & Lagos, Nigéria \\
\hline $50 \mathrm{mil}$ & Yeshu Darbar & Rajendra B. Lal & Allahabad, Índia \\
\hline $50 \mathrm{mil}$ & New Life & S. Joseph & Bombai, Índia \\
\hline $50 \mathrm{mil}$ & Nambu Full Gospel Church & Não Informado & Anyang, Coréia do Sul \\
\hline $45 \mathrm{mil}$ & Catedral Evangelica de Santiago & Eduardo D. Castro & Santiago, Chile \\
\hline
\end{tabular}

Fonte: http://noticias.gospelmais.com.br/estudo-mega-templos-evangelicos-listagrandes-igrejas-mundo-30631.html

No Brasil, o surgimento dos megatemplos cresceu acentuadamente nos anos 1980, quando as igrejas evangélicas passaram a comprar grandes salas de cinema abandonadas, com capacidade para até 2 mil pessoas.

$\mathrm{Na}$ década de 90 surgiram edifícios religiosos majestosos como a Catedral Mundial da Fé, sede da Igreja Universal do Reino de Deus, no Rio de Janeiro e, posteriormente, o megatemplo da Igreja do Poder de Deus (IMPD) e, mais recentemente, o Templo de Salomão (IURD) que revela a grandiosidade e pompa por excelência desses empreendimentos, conforme quadro 1.

Quadro 1 - Alguns detalhes do Templo de Salomão ${ }^{5}$

\begin{tabular}{|l|l|}
\hline Características & \multicolumn{1}{|c|}{ Detalhes } \\
\hline $\begin{array}{l}\text { Inauguração: } \\
\text { Grandiosidade, } \\
\text { poder e pompa. }\end{array}$ & $\begin{array}{l}\text { Inaugurado em 31 de julho de 2014, na cidade de São Paulo, } \\
\text { contou com a presença de políticos, jornalistas, pastores, fiéis e } \\
\text { demais stakeholders. }\end{array}$ \\
\hline $\begin{array}{l}\text { Alcance da obra: } \\
\text { Maior espaço religioso } \\
\text { do Brasil }\end{array}$ & $\begin{array}{l}\text { A obra durou 4 anos e custou por volta de R\$ 680 milhões. Foram } \\
\text { comprados cerca de 40 imóveis no bairro do Brás pela IURD. O } \\
\text { Templo foi construído em um terreno de 35 mil metros quadrados, } \\
\text { o equivalente a 5 campos de futebol, com capacidade para 10 mil } \\
\text { pessoas, sendo considerado o posto de maior espaço religioso do } \\
\text { país em área construída, que é quatro vezes maior do que o } \\
\text { Santuário Nacional de Aparecida (SP). Aparecida tem 23,3 mil } \mathrm{m}^{2} \\
\text { de área construída, enquanto o Templo Salomão tem 100 mil } \mathrm{m}^{2} .\end{array}$ \\
\hline Artefatos: & O altar foi construído no formato da Arca da Aliança, local onde \\
\hline
\end{tabular}

5 Para se ter uma visão mais abrangente da magnitude do Templo de Salomão acessar o link: http://indexmp3.xyz/search/templo-de-salom\%C3\%A3o-3d-por-agenor-santos.html

Comun. \& Inf., Goiânia, GO, v. 19, n. 2, p. 106-126, jul./dez. 2016. 


\begin{tabular}{|l|l|}
\hline $\begin{array}{l}\text { Precisão nos detalhes } \\
\text { bíblicos. }\end{array}$ & $\begin{array}{l}\text { teriam sido guardados os Dez Mandamentos, segundo a Bíblia. } \\
\text { Cem metros quadrados de vitrais dourados foram instalados acima } \\
\text { do altar. Nas paredes há grandes menorás - candelabros de sete } \\
\text { braços. As cadeiras que vão acomodar os milhares de fiéis foram } \\
\text { trazidas da Espanha. Dez mil lâmpadas de LED foram instaladas } \\
\text { no teto do salão principal. Foram importadas de Hebron, em Israel, } \\
40 \text { mil metros quadrados de pedras usadas na construção e } \\
\text { decoração do Templo. Também doze oliveiras foram importadas } \\
\text { do Uruguai para reproduzir o Monte das Oliveiras. }\end{array}$ \\
\hline $\begin{array}{l}\text { Funcionalidade: } \\
\text { tecnologia e comodidade. }\end{array}$ & $\begin{array}{l}\text { O estacionamento do templo conta com 2000 vagas para carros, } \\
\text { 241 para motos e 200 para ônibus. Na área construída há ainda } \\
\text { espaço para 60 apartamentos de pastores que estão a trabalho no } \\
\text { templo - incluindo um para o principal líder da igreja, o bispo Edir } \\
\text { Macedo. No altar, há uma esteira rolante destinada a carregar o } \\
\text { dízimo pago pelos fiéis diretamente para uma sala-cofre, }\end{array}$ \\
\hline $\begin{array}{l}\text { Além do Templo, há também um museu, chamado de Memorial, } \\
\text { no qual, 12 colunas explicam a origem das 12 tribos de Israel. } \\
\text { himbolismo } \\
\text { histórico. }\end{array}$ & resgate \\
\hline
\end{tabular}

Fonte: autores com base nos dados divulgados em Souza (2014)

Para Smith e Campos (2014), o Templo de Salomão representa a imagem de grandeza que os lideres da IURD querem projetar sobre a igreja, que por cerca de uma década tem sido relativamente ofuscada por outras denominações religiosas (que também construíram seus megatemplos) como a Igreja IMPD e a IIGD, dentre outras.

\section{REFERENCIAL TEÓRICO}

Bourdieu e Miceli (1987), por um lado, concebem o campo cultural como um mercado de trocas simbólicas, mais uma vez funcionando nos moldes da lei da oferta e da procura, de acordo com as especificidades dos agentes envolvidos, por outro, do ponto de vista do receptor da mensagem, o signo e não o objeto é consumido por intermédio das marcas que lhe são apresentadas; por outro, o mercado produtor, o fator concorrência se torna um jogo se soma zero ${ }^{6}$, isto é, o ganho de um determinado agente tende a representar perdas para os demais, conforme quadro 2.

Quadro 2 - Fatores no mercado de bens simbólicos

1.Todas as organizações de bens simbólicos estão em constante luta pela conquista da mente do consumidor;

2. O que uma organização ganha em adesão representa perdas para outros concorrentes;

3. Como o comportamento do consumidor desses bens tende à irracionalidade, é bastante comum o emprego de técnicas subliminares;

\footnotetext{
${ }^{6}$ Em termos mercadológicos, os fatores presentes no mercado de bens simbólicos constituem "jogo de soma zero", noção econômica introduzida na teoria de Neumann \& Morgenstern (1953), visto que, toda a sua teoria está voltada aos jogos nos quais um ou alguns dos competidores, para ganhar, deve levar necessariamente o (s) adversário (s) à derrota.
}

Comun. \& Inf., Goiânia, GO, v. 19, n. 2, p. 106-126, jul./dez. 2016. 
4. Em virtude da própria antropofagia do mercado, não raras vezes a opção de extinguir a concorrência é a única forma de sobrevivência.

Fonte: Bazanini (2005, p. 179).

Esses quatro fatores concorrenciais estão presentes em todos os mercados de bens simbólicos: religiosos, culturais, desportivos, etc. Por isso, para se alcançar vantagem competitiva os relacionamentos adequados com os stakeholders constitui a essência dinâmica das características desse mercado.

\subsection{A TEORIA DOS STAKEHOLDERS}

O termo stakeholder surgiu em 1963 em um memorando interno do Stanford Research Institute e se referia a "grupos que sem o seu apoio à organização deixaria de existir" (FREEMAN; REED, 1983, p. 89). A concepção que embasa essa visão de realidade organizacional pode ser resumida na ideia, segundo a qual, além dos acionistas (e/ou proprietários), a organização também é responsável por outros grupos que possuem interesses nas ações da organização.

Decorrentes dessas visões, duas definições básicas sobre os stakeholders são propostas: uma ampla e outra, mais estrito. O primeiro afirma que stakeholder é todo grupo ou indivíduo que influencia ou é influenciado pelo alcance dos objetivos da organização; o segundo, refere-se a indivíduos ou grupos que a organização depende para a sua sobrevivência.

A definição mais ampla, isto é, a ideia de que stakeholder influencia ou é influenciado pela ação dos demais agentes é adotada por muitos autores como clássica e serve como ponto de partida para suas análises ou críticas (cf. DONALDSON e PRESTON, 1995; MITCHELL, AGLE e WOOD, 1997; FREEMAN, WICKS, PARMAR e MCVEA, 2004; PHILLIPS, 2007; FREEMAN, HARRISON e WICKS, 2007, FROOMAN, 2010).

Dentre esses autores, para os propósitos desse artigo serão empregadas as abordagens Salience Model Stakeholder (MITCHEL, WOOD, 1997) acompanhada dos conceitos de stakeholder normativo, stakeholder derivativo e não-stakeholders (PHILLIPS, 2007).

\subsubsection{A perspectiva do Salience Model}

Mitchell, Agle e Wood (1997) propuseram o Salience Model, no qual definiram que é preciso classificar os stakeholders em termos de poder, legitimidade e urgência. Este critério 
de diferenciação dos grupos de stakeholders permite estabelecer prioridades e definir quais os interesses que serão atendidos.

No modelo proposto é sugerido que o comportamento estratégico de uma organização está sujeito a diversos grupos envolvidos, e as estratégias da organização devem satisfazer as necessidades desses grupos na relação de seu poder, legitimidade e urgência.

Poder: habilidade para levar alguém a fazer alguma coisa que ele não teria de fazer sem ser solicitado que pode ser coercivo (força ou ameaça), normativo (legislação, meios de comunicação) ou utilitário (detém recursos ou informações). Legitimidade: percepção generalizada de que as ações de uma entidade são desejáveis ou apropriadas, de acordo com o contexto socialmente construído; pode ser individual, organizacional ou social. Urgência: necessidade imediata de ação que determina o tempo de resposta da organização quanto às solicitações dos stakeholders; ou seja, fator tempo (necessidade de velocidade na resposta da organização) e criticalidade (importância do clamor ou do relacionamento da empresa com o stakeholder); que conferem dinâmica ao modelo, conforme quadro 3.

Quadro 3 - Tipologia dos stakeholders no Salience Model

Stakeholders Latentes. Possuem somente um dos atributos (ou poder, ou legitimidade ou urgência), provavelmente recebem pouca atenção da empresa.

Stakeholders Expectantes. Possuem dois atributos (ou poder e legitimidade, ou poder e urgência, ou urgência e legitimidade) o que leva a uma postura mais ativa do stakeholder e em consequência, maior atenção da própria empresa.

Stakeholder Definitivo. Possuem os três atributos (poder + legitimidade + urgência), por isso, recebem a máxima atenção da empresa.

Não-Stakeholder (não possui nenhum dos atributos).

Fonte: Adaptado de Mitchell, Agle e Wood, (1997, p. 875)

No Brasil, os detratores críticos, geralmente, são representados pelas igrejas de pequeno porte e igrejas históricas tradicionais (Igreja Batista e Metodista) e Igrejas Pentecostais (Assembleia de Deus, Congregação Cristã no Brasil, Igreja do Evangelho Quadrangular, Igreja Brasil para Cristo, Igreja Deus e Amor, dentre outras). Os detratores que eram ex-aliados são representados pelas Igrejas neopentecostais [Igreja Internacional da Graça de Deus (IIGD), Igreja Renascer em Cristo (IRC), Igreja Mundial do Poder de Deus (IMPD)].

Comumente, no mercado de bens simbólicos da religião, a IURD apregoa a prosperidade, a IIGD, o triunfalismo, a IMPD, a experiência mística; a IRC, a juvenilização da mensagem cristã. $\mathrm{O}$ primeiro se denomina bispo, o segundo, missionário, o terceiro e quarto, apóstolos.

Comun. \& Inf., Goiânia, GO, v. 19, n. 2, p. 106-126, jul./dez. 2016. 
$\mathrm{Na}$ disputa retórica da defesa da teologia da prosperidade, do triunfalismo, da experiência mística e juvenilização os ataques, defesas, omissões, testemunhos, montagens, dissimulações são recursos frequentemente utilizados para conquistar posicionamento favorável perante os stakeholders no qual prevalece: o sentido hierárquico dos temas e das soluções que buscam de maneira agonística o resultado mais eficaz sob a ótica da opinião pública independentemente do critério do verdadeiro e do falso; a tendência de considerar os temas em sua globalidade, direcionando-os para a perspectiva favorável aos interesses da organização; a agressividade polêmica pela qual não se admite qualquer solução diferente daquela que beneficia os interesses da organização em luta pelo seu espaço.

Para alcançar tal intuito, prevalece o estilo combativo (stylus pugnax) ${ }^{7}$ revelador de aspectos característicos da arte retórica, isto é, importa encontrar argumentos cada vez mais convincentes para conquistar a opinião pública de sua legitimidade, franqueza e lealdade na defesa do bem comum, embora pouco importa se esses mesmos argumentos sejam reais ou fictícios, éticos ou não éticos, uma vez que, o emprego do blefe e da ética utilitarista se tornam dominantes, cujo axioma se traduz na expressão: a verdade é aquilo que beneficia os interesses da organização.

[“...”] fundada numa situação necessariamente agonística, não se pode prescindir de um stylus pugnax, de um estilo combativo, e que este agonismo discursivo em si não a desqualifica, mas, antes, parece ser uma propriedade de toda interlocução (GOMES, 1994, p. 129).

As situações agonísticas se caracterizam por um jogo de soma zero, isto é, o ganho de alguns representam perdas para os demais, por isso, é preciso relevar os aspectos referentes às obrigações morais presentes nesses embates. Phillips (2007) faz inúmeras críticas ao Salience Model ao apontar a problemática de se fazer referência a grupos com poder com os quais não se têm obrigações morais, mas que podem influenciar de modo significativo a organização, como um grupo não legítimo, conforme figura 1.

\footnotetext{
7 Stylus Pugnax, em consonância com o conceito "jogo se soma zero", caracterizado por ataques verbais, inclusive o blefe, para se consolidar como "persona grata" perante à opinião pública. O blefe foi estudado em termos teóricos por Von Neumann. Cf. NEUMANN \& MORGENSTERN (1953).
}

Comun. \& Inf., Goiânia, GO, v. 19, n. 2, p. 106-126, jul./dez. 2016. 
Figura 1 - Mapa dos stakeholders: normativos, derivativos e não-stakeholder

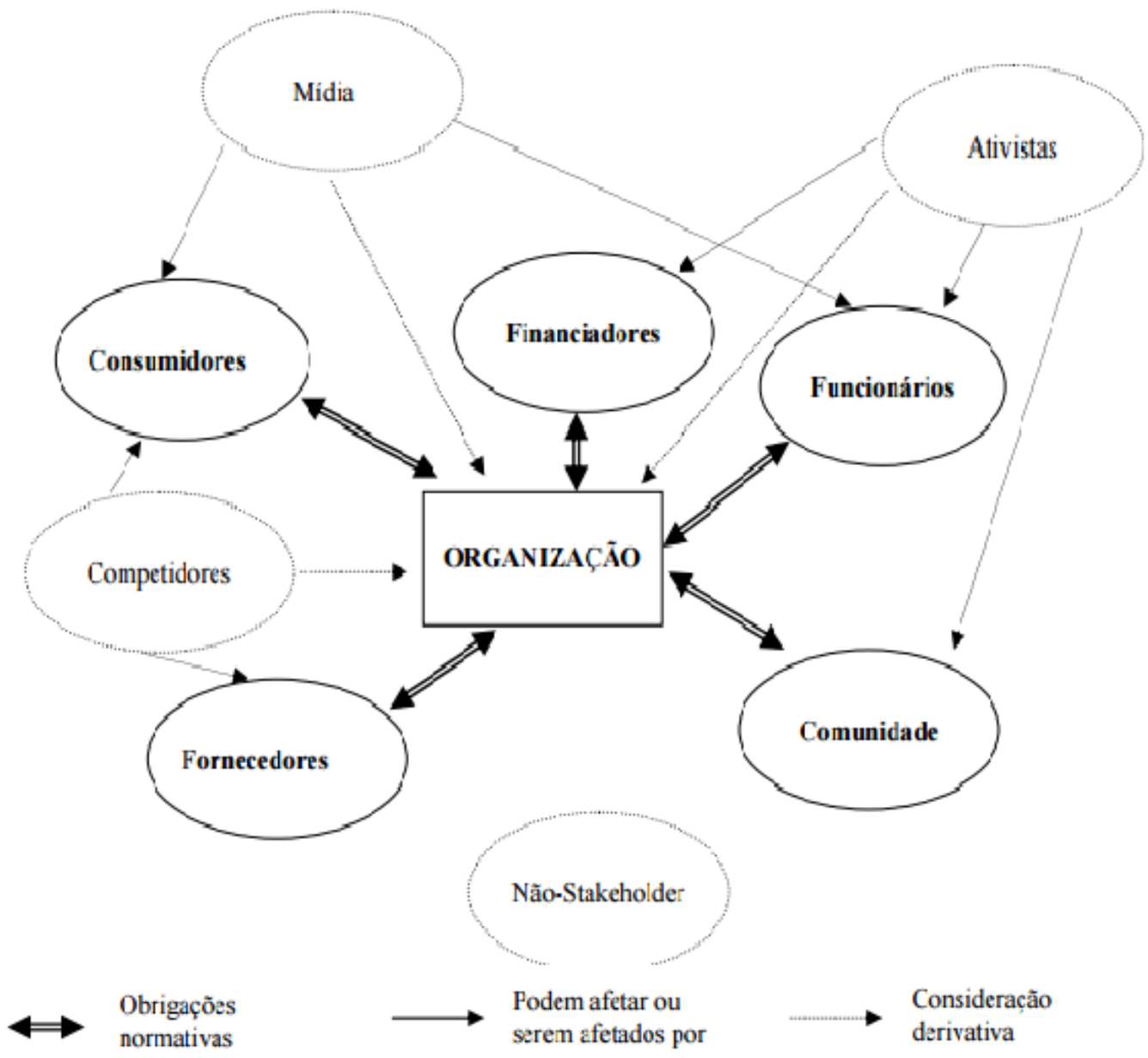

Fonte: Phillips (2007, p. 181)

Os stakeholders normativos são definidos como "aqueles a quem a organização tem uma obrigação moral, uma obrigação de equidade entre os stakeholders, superior aquele devido a outros atores sociais" (PHILLIPS 2007, p. 173). Os stakeholders derivativos são definidos como "aqueles grupos cujas ações e reivindicações devem ser levadas em conta pelos gerentes devido ao seu efeito potencial sobre a organização e seus stakeholders normativos" (PHILLIPS 2007, p. 174).

Nessa perspectiva, a legitimidade desses grupos está em sua capacidade de influenciar a organização e seus stakeholders normativos, ou seja, sua legitimidade não deriva de si mesmas, mas de sua influência potencial. Portanto, não há qualquer obrigação moral da parte da organização de se preocupar com o seu bem-estar e podem ser tratados exclusivamente de forma instrumental (D’ORAZIO, 2006).

Comun. \& Inf., Goiânia, GO, v. 19, n. 2, p. 106-126, jul./dez. 2016. 
Com o intuito de resolver esse impasse, o autor então sugere uma distinção entre legitimidade do stakeholder normativo e legitimidade do stakeholder derivativo para fornecer uma posição ao debate "perspectiva ampla versus perspectiva estrita" que reconheça simultaneamente as obrigações morais das organizações em relação a alguns grupos de stakeholders e a legitimidade pragmática baseada no poder, predominante da teoria das organizações.

Tal qual na perspectiva de Mitchel, Agle e Wood (1997), também para Phillips (2007) quando o indivíduo ou grupo não exerce nenhuma influência nem é influenciado pela operação da organização, os não-stakeholders são definidos como grupos ou indivíduos em relação aos qual a organização não tem qualquer obrigação moral e a probabilidade deles terem um impacto sobre a organização ou em seus stakeholders legítimos é muito pequena.

\section{PROCEDIMENTOS METODOLÓGICOS}

Por intermédio de pesquisa exploratória, de natureza qualitativa, o objetivo da pesquisa está em analisar a importância do templo de Salomão para a Igreja Universal do Reino de Deus (IURD) como viabilidade política e midiática de uma empresa religiosa inserida mercado de bens e serviços religiosos para o alcance de vantagem competitiva.

A pesquisa foi realizada em maio de 2015 na cidade de São Paulo. A amostra foi composta por três profissionais de marketing que atuam também como prestadores de serviços de media training para organizações religiosas, conforme quadro 4.

Quadro 4 - Questões da pesquisa

1. Quem são os principais agentes envolvidos nas atividades presentes no Templo de Salomão?

2. Como podem ser entendidos os atributos de Poder, legitimidade e Urgência dos agentes envolvidos?

3. Em termos políticos e midiáticos, como o Templo de Salomão repercute entre os stakeholders?

Fonte: elaborado pelos autores

Essas três questões abertas permitiram aos entrevistados manifestar seu entendimento de forma livre sem qualquer interferência dos pesquisadores. Com a permissão dos entrevistados as respostas foram gravadas e, posteriormente agrupadas e sistematizadas. Por solicitação dos entrevistados as respostas foram referenciadas pelas letras E1 (entrevistado 1); E2 (entrevistado 2); E3 (entrevistado 3).

Desse modo, foi possível manter o anonimato e assim, maior liberdade de expressão, visto que, esses profisssionais prestam serviços para organizações religiosas.

Comun. \& Inf., Goiânia, GO, v. 19, n. 2, p. 106-126, jul./dez. 2016. 


\section{RESULTADOS DA PESQUISA}

Os resultados da pesquisa remetem a ideia de que o Templo de Salomão representa uma situação real de mercado competitivo capaz de influenciar as estruturas das organizações religiosas e repercute favoravelmente em seus aspectos de visibilidade política e midiática.

Na percepção dos entrevistados, os principais stakeholders são o Governo Federal e as autoridades pelo poder de coerção que podem exercer sobre os líderes do templo, a Bancada Evangélica pelo suporte à ideologia da igreja que, na perspectiva do Salience Model são possuidores de poder, legitimidade e urgência. Esses dois stakeholders são stakeholders definitivos, para os quais os gestores devem dispensar atenção imediata.

Em relação ao poderio desses stakeholders, as falas de E1 e E2 foram reveladoras:

Na noite de 31 de julho, na inauguração do Templo de Salomão, os políticos tiveram lugar de destaque. A figura profética do líder do principal líder Igreja, Edir Macedo, acompanhado pela presidenta da República, pelo vicepresidente, pelo governador e prefeito de São Paulo, parecia mais um compromisso diplomático do que a inauguração de uma igreja (E1).

A postura do Edir Macedo mostra o quanto os governantes e políticos estão envolvidos com o empreendimento da Universal e com os representantes da Bancada Evangélica, cuja atenção era de total atenção e dependência (E2).

Os doadores possuem poder, a mídia e os concorrentes possuem poder e/ou legitimidade, por isso, são considerados stakeholders dominantes que deve merecer atenção da organização, todavia, quando o stakeholder concorrente assume abertamente a posição de detrator, sejam ex-aliados que se tornaram concorrentes ou críticos radicais das práticas da religião de mercado, em ambos os casos, necessitam de acompanhamento contínuo. Os primeiros, pela tendência de agressão mútua; os últimos, por considerar a criação e as atividades mercadológicas presentes nos megatemplos como reflexo da decadência dos valores cristãos num mundo corrompido, conforme quadro 5.

Quadro 5 - Stakeholders latentes: críticos radicais da religião de mercado

\section{As críticas mais contundentes}

1. O culto a Deus será substituído pela pujança do espaço físico.

2. A majestade do templo certamente receberá peregrinações semelhantes a um lugar santificado.

3. Retoma-se o comércio da fé como os antigos vendilhões do templo expulsos por Jesus.

4. Privilegiar o Velho Testamento é um retrocesso da fé cristã.

5. Embora pareça cristão, o templo de Salomão ressalta a pompa em detrimento da caridade.

6. Deus não está em templos feitos por mãos humanas, mas habita em pessoas através de seu Espírito. Os cristãos são o verdadeiro templo do Espírito de Deus.

7. Idolatria: o templo abrigará a tumba da família do líder da organização, Edir Macedo.

Comun. \& Inf., Goiânia, GO, v. 19, n. 2, p. 106-126, jul./dez. 2016. 
Fonte: autores com base nas respostas dos entrevistados.

Desse modo, os detratores críticos dos megatemplos representam os stakeholders latentes por possuir somente um dos atributos (poder, legitimidade, urgência), são menos impactantes que os detratores dos megatemplos que eram ex-aliados e que correspondem aos stakeholders expectantes que tendem a ser bastante agressivos, pois, incessantemente colocam em dúvida o caráter moral dos concorrentes por meio supostos delitos, conforme quadro 6 .

Quadro 6 - Stakeholders Expectantes: os detratores que eram ex-aliados

\section{As críticas mais contundentes}

1. Denunciam a corrupção, a ganância e a ambição dos líderes religiosos concorrentes.

2. Afirmam que os milagres são aparências enganadoras dos falsos profetas.

3. Acusam os líderes concorrentes de possuírem contas secretas em paraísos fiscais.

Fonte: autores com base na resposta dos entrevistados.

No Brasil, os detratores críticos, geralmente, são representados pelas igrejas de pequeno porte e igrejas históricas tradicionais (Igreja Batista e Metodista) e Igrejas Pentecostais (Assembleia de Deus, Congregação Cristã no Brasil, Igreja do Evangelho Quadrangular, Igreja Brasil para Cristo, Igreja Deus e Amor, dentre outras).

Os detratores que eram ex-aliados são representados pelas Igrejas neopentecostais (IIGD, IRC, IMPD, dentre outras). Possuem em comum o fato de serem adeptos da teologia da prosperidade e também da ênfase nas guerras espirituais.

Eles afirmam estarem destinados a prosperidade, à saúde, à vitória, à felicidade. Para alcançar tais bênçãos, garantir a salvação e afastar os demônios de sua vida, basta o cristão ter fé incondicional e inabalável em Deus, exigir seus direitos em alta voz, ser obediente e fiel no pagamento dos dízimos (MARIANO, 1999, p.160).

Nessas disputas, a IIGD e a IRC têm se mantido afastadas do embate direto (stylus pugnax) com as demais. Todavia, a IMPD expõe radical e continuamente suas divergências, principalmente em conversas com os demônios que dizem estar nas concorrentes (COUTINHO, 2012).

Em relação à disputa retórica nas atividades nos megatemplos entre a IURD e a IMPD, as semelhanças nas nomenclaturas e nas programações internas são bastante esclarecedoras, conforme quadro 7 e 8 . 
Quadro 7 - Comparação de Nomenclaturas

\begin{tabular}{|l|l|l|l|}
\hline & Nome & \multicolumn{1}{|c|}{$\begin{array}{c}\text { Nomenclatura dos } \\
\text { Templos }\end{array}$} & Nomenclatura da fachada da igreja \\
\hline IMPD & $\begin{array}{l}\text { Igreja } \\
\text { Mundial do } \\
\text { Poder de } \\
\text { Deus }\end{array}$ & Cidade Mundial & Jesus Cristo é o mesmo ontem, hoje e sempre. \\
\hline IURD & $\begin{array}{l}\text { Igreja } \\
\text { Universal } \\
\text { do Reino } \\
\text { de Deus }\end{array}$ & Templo de Salomão & Jesus Cristo é o Senhor. \\
\hline
\end{tabular}

Fonte: Rocha (2014, p. 81).

Quadro 8 - Comparação de Eventos

\begin{tabular}{|l|l|}
\hline \multicolumn{1}{|c|}{ IMPD } & IURD \\
\hline $\begin{array}{l}\text { Presença de Deus (Domingo): Afirmam que Deus } \\
\text { está presente em suas reuniões. }\end{array}$ & $\begin{array}{l}\text { Encontro com Deus (Domingo): Afirmam que } \\
\text { terão um encontro com Deus. }\end{array}$ \\
\hline $\begin{array}{l}\text { Clamor pelo crescimento financeiro (Segunda- } \\
\text { feira): Orações, ofertas, dízimos, campanhas } \\
\text { voltadas para a prosperidade financeira das } \\
\text { pessoas. }\end{array}$ & $\begin{array}{l}\text { Encontro da Prosperidade (Segunda-feira): } \\
\text { Evento voltado para oração e doação em busca da } \\
\text { prosperidade: enriquecimento. }\end{array}$ \\
\hline $\begin{array}{l}\text { Clamor pelas bênçãos na família (Quinta-feira): } \\
\begin{array}{l}\text { Orações de mulheres que foram abandonadas } \\
\text { pelos maridos. Orações pelos filhos denominados } \\
\text { rebeldes. }\end{array}\end{array}$ & $\begin{array}{l}\text { Terapia do Amor (Quinta-feira): Palestras para } \\
\text { cônjuges. Orações pela família. }\end{array}$ \\
\hline $\begin{array}{l}\text { Clamor pela libertação (Sexta-feira): Combate a a } \\
\text { vícios, retirada do mal. }\end{array}$ & $\begin{array}{l}\text { Culto da Libertação: Exorcismos, promessas de } \\
\text { cura (libertação da doença), promessas de } \\
\text { enriquecimento (libertação da pobreza). }\end{array}$ \\
\hline $\begin{array}{l}\text { Milagre-Urgente (Terça-feira): Reunião voltada } \\
\text { para pessoas que necessitam de um milagre (algo } \\
\text { sobrenatural). }\end{array}$ & $\begin{array}{l}\text { Jejum das causas impossíveis (Sábado): Pessoas } \\
\text { que buscam a solução dos problemas, } \\
\text { considerados impossíveis. }\end{array}$ \\
\hline
\end{tabular}
Fonte: Rocha (2014, p. 81).

As comparações das nomenclaturas e dos eventos apontam para a necessidade de imitação das igrejas concorrentes. Pelas semelhanças que se evidenciam, é possível inferir a presença das sinonímias, isto é, palavras distintas que possuem o mesmo significado, acompanhado de características marcadamente miméticas no mercado de bens simbólicos da religião, tais como: Igreja Universal do Reino de Deus e Igreja Mundial do Poder de Deus (Universal e Mundial, Poder de Deus e Reino de Deus são palavras sinônimas); Cidade de Deus e Templo de Salomão (o Templo de Salomão remete à Cidade de Deus e, reciprocamente, a Cidade de Deus corresponde à majestade do Templo de Salomão); Jesus Cristo é o Senhor e Jesus Cristo é o mesmo ontem, hoje (O Senhor é absoluto em sua majestade além do tempo, ou seja, ontem, hoje e eternamente).

Comun. \& Inf., Goiânia, GO, v. 19, n. 2, p. 106-126, jul./dez. 2016. 
Portanto, as práticas de devoção da IMPD são reapropriadas de outras religiões e denominações evangélicas, notadamente da IURD.

Figura 2 - Stakeholders das organizações religiosas

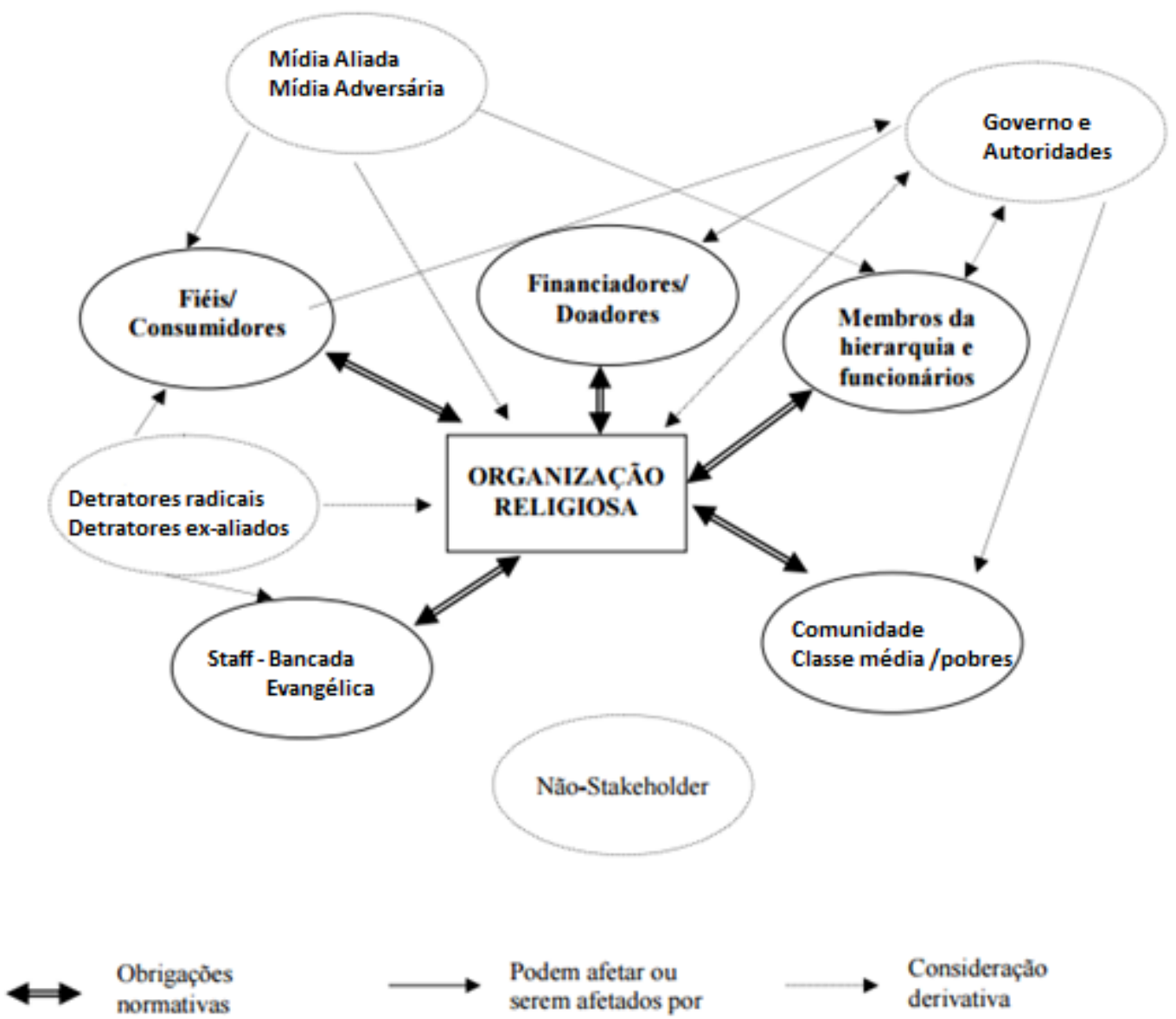

Fonte: autores com base em Philips (2007).

Nessa perspectiva, dentre os ex-aliados, a IMPD, em relação aos interesses da IURD pode ser classificada como stakeholder derivativo, enquanto a IIGD e IRC como stakeholder normativo, pela não agressão explícita.

Com base nos conceitos de stakeholders normativos e stakeholders derivativos, na presente pesquisa, o referido modelo genérico do autor foi atualizado em decorrência das respostas dos entrevistados e das próprias mudanças que, nessa década, ocorreram a partir do surgimento de novos elementos que podem ser incorporados ao modelo, conforme proposto na figura 2.

Em relação aos detratores críticos, as reflexões de E1 e E3 são esclarecedoras: 
$\mathrm{Na}$ inauguração do templo, os lideres das igrejas tradicionais se encolheram, como se não devesse dar nenhuma importância a esse evento, pois, toda essa pompa dos "fariseus" e "vendilhões do templo" remetem apenas a decadência da mensagem cristã (E1).

(“...”) Pastores de igrejas tradicionais como, por exemplo, a "Igreja Deus é amor" apregoavam que estávamos diante do surgimento do anticristo e que era preciso estar atento para o fim do mundo (E3).

Em relação aos detratores ex-aliados, alguns pontos foram nomeados como críticos:

Não vai ser fácil para a Universal alimentar o templo de Salomão sem alianças com os políticos e com o poder público, pois, o templo foi construído de forma irregular, sem alvará de funcionamento e, esse perdão, só vai ser possível por meio de muita negociação (E2).

O Templo da Igreja Mundial do Poder de Deus foi interditado várias vezes pela falta de habilidade na negociação com o poder público, lobistas e líderes de outras denominações evangélicas. (E3).

Numa perspectiva epistemológica, as falas dos entrevistados remetem a visão de que a visão do Salience Model precisa ser atualizada continuamente para se tornar mais efetiva no relacionamento com os stakeholders, confirmando a visão de Phillips (2007) em distinguir os stakeholders normativos dos stakeholders derivativos e não-stakeholders.

Quanto à viabilidade política e midiática da religião de mercado na figura de um "Deus onipresente nos meios de comunicação", Roncari afirmou:

Se Deus quiser existir, tem que aparecer na televisão, e se quiser se fazer ouvir, não é mais suficiente a palavra, ela tem que converter-se em imagem (...) se a Igreja não fizer presente nas telas deixará de participar do mundo criado pela TV, um mundo quase a parte que forma hoje o imaginário da maior parte da população (RONCARI, 1994, p.32).

Em termos mercadológicos essa citação pode ser transportada para a criação dos megatemplos, visto que, o axioma proposto é que os seres humanos possuem necessidades e aspirações a serem satisfeitas, tanto em nível físico quanto em nível simbólico, sendo essa a razão de ser das instituições, cuja finalidade imperiosa é atender as necessidades humanas porque, necessidades insatisfeitas ${ }^{8}$ (inclusive em relação ao divino) impulsionam as pessoas em direção às novas propostas e soluções.

\section{CONSIDERAÇÕES FINAIS}

\footnotetext{
${ }^{8}$ Necessidades insatisfeitas, no "jogo de soma zero", corresponde ao favorecimento dos interesses dos concorrentes possuidores dos atributos desejados pelo público. Nesse sentido, os megatemplos das organizações religiosas podem ser concebidos como corolários da teologia da prosperidade e, consequentemente, elemento para alcance de vantagem competitiva.
}

Comun. \& Inf., Goiânia, GO, v. 19, n. 2, p. 106-126, jul./dez. 2016. 
Ao final desse trabalho é possível conceber que a gestão de megatemplos, por estar inserida na lógica capitalista, busca identificar aliados e detratores, parcerias e rupturas e as distinções entre os stakeholders normativos, derivativos envolvidos no processo num jogo de soma zero, isto é, o ganho de determinados grupos representa perdas para os outros.

Na perspectiva do marketing, a construção do Templo de Salomão constitui um "edifício de representação simbólica" que parece elevar-se sobre a realidade da vida cotidiana, garantindo-lhe uma nomização peculiar, ou seja, um enquadramento a padrões socialmente legítimos de conduta, de significado e valor a vida competitiva do homem moderno, em cujo espaço os produtos e serviços apresentados na forma de espetáculo faz com que a religião seja orientada não mais a partir do sagrado (misterium tremendum), mas das leis regentes do mercado, no qual a oferta/demanda se tornam prioridades nas agendas do discurso simbólico de cada sistema, por isso, precisa ser gerido com eficiência, diante de um mercado altamente antropofágico, no qual, diferentes stakeholders estão presentes.

Em termos pragmáticos, a viabilidade política e midiática pode ser explicada na dinâmica psicossocial de nossa pós-modernidade, na qual. as esferas da vida estão submetidas a uma organização econômica, da qual, a vida religiosa passa a se tornar uma ferramenta para que o sujeito moderno possa alcançar seus objetivos afetivos, profissionais e existenciais. Nesse cenário, os fiéis buscam instituições que contemplem suas necessidades espirituais e propicie orientações diante da situação da precariedade social de uma forma imediatista e consumista, na qual a fé é utilizada como um meio para se alcançar ascensão social pela adequação à lógica capitalista, ou seja, uma forma de adaptação do indivíduo à sociedade pósmoderna, de forma doutrinária e reducionista, através da igreja o sujeito se torna "fiel", doando sua identidade para o coletivo, tornando-se membro de um grupo.

Portanto, a estratégia de marketing na construção dos megatemplos, enquanto esfera simbólica da sociedade acompanha as transformações da modernidade, na qual a vida ganha um novo significado ao se tornar dinâmica e imediatista, em uma mudança tão impactante que não abre espaço para a reflexão crítica, cuja ideologia voltada para o consumo (teologia da prosperidade) se torna parte integrante da vida social dos indivíduos e o sentimento de religiosidade, fé e crença adquirem caráter mercadológico.

Para futuras pesquisas sugerem-se estudos mais aprofundados referentes às alianças entre os líderes dos megatemplos e os membros da bancada evangélica que representam um dos principais stakeholders normativos no mercado de bens simbólicos da religião. 


\section{REFERÊNCIAS}

AMIGO, R. New Religious Spaces in the Megacity: The Igreja Universal do Reino de Deus and its Temple of Solomon in São Paulo, Brazil. Zeitschrift für junge Religionswissenschaft 9:5-21, 2014.

BAZANINI, R. Globo e universal: tudo a ver: A disputa mercadológica pelo controle do imaginário popular ofensiva e contraofensiva retórica, Universidade Católica (tese de doutoramento em comunicação e semiótica), São Paulo: 1998.

BAZANINI, R. O ensino de filosofia como um processo existencial humano. O Método Bazanini no ensino de filosofia. Filosofia aplicada à administração. São Paulo: Plêiade, 2005.

BERGER, P.; LUCKMANN, T. Modernidade, pluralismo e crise de sentido. Petrópolis: Editora Vozes, 2004.

BIARD, J. The good and bad religion lite. Disponível em: $<$ http://www.smh.com.au/news/opinion/the-good-and-bad-ofreligionlite/2006/02/22/1140563858123.html>. Acesso em: 12 jul. 2015.

BOURDIEU, P; MICELI, S. A economia das trocas simbólicas. São Paulo: Perspectiva, 1987.

COUTINHO, L. O diabo entra na briga entre Edir Macedo e Valdemiro. Veja, São Paulo, 24 mar. 2012. Disponível em: $<$ http://veja.abril.com.br/noticia/brasil/o-diabo-entra-na-brigaentre-edir-macedo-e-valdemiro/>. Acesso em: 13 set. 2015.

MOREIRA, A. S. A religião sob o domínio da estética. Horizonte, Belo Horizonte, v. 13, n. 37, p. 379-405, 2015.

OLIVEIRA, D. P. R. Sistemas, organização e métodos: uma abordagem gerencial. São Paulo, Atlas, 2002.

DONALDSON, T.; PRESTON, L. The stakeholders theory of the corporation: concepts, evidence and implications. Academy of Management Review ,Mississipi State,v.20, jan.1995.

D'ORAZIO, E. (Org.). New perspectives on the stakeholder view of the firm and global corporate citizenship. Notizie di Politeia, v. 22, n. 82, 2006.

FREEMAN, R. E. HARRISON, J. S.; WICKS, A. C. Managing for stakeholders: Survival, reputation, and success. Yale University Press, 2007.

FREEMAN, R. E.; REED, D. L. Stockholders e stakeholders: A new perspective on corporate governance. California Management Review, v. 25, n. 3, p. 88-106, 1983. 
FREEMAN, R. E.; WICKS, A.; PARMAR, B.; MCVEA, J. Stakeholder Theory: The State of the Art and Future Perspectives. In: D'ORAZIO, E. (Org.). Business ethics and corporate social responsibility in a global economy. Notizie di Politeia, v. 20, n. 74, 2004. p. 9-22.

FROOMAN, J. The issue network: Reshaping the stakeholder model. Canadian Journal of Administrative Sciences/Revue Canadienne des Sciences de l'Administration, v. 27, n. 2, p. 161-173, 2010.

GOMES, W. Estratégia retórica e ética da argumentação na propaganda política. Brasil: comunicação, cultura e política. Rio de Janeiro, Diadorim, p. 117-133, 1994.

JADON, J.C. Sucesso e salvação-estudo semiótico comparativo entre os discursos televisivos das Igrejas Universal do Reino de Deus e Católica Apostólica Romana no Brasil. 2009. Tese de Doutorado. Universidade de São Paulo, 2009.

MAGALDI, W. Dinheiro, saúde e sagrado. 2. ed. São Paulo: Eleva Cultural, 2009.

MARIANO, R. Neopentecostais: sociologia do novo pentecostalismo no Brasil. São Paulo, Loyola, 1999.

McCARTHY, J. Basic marketing and management approach, 5 th Richard D. Irwin, Homewood, 1998.

MIKLOS, J. Ciber-religião: a construção de vínculos religiosos na cibercultura. São Paulo: Ideias e Letras, 2012.

MILLER, K. D. Competitive strategies of religious organizations. Strategic Management Journal, v. 23, n. 5, p. 435- 456, 2002.

MITCHELL, K;, AGLE, R.; WOOD, D. J. Toward a theory of stakeholder identification and salience. Defining the principle of Who and what really counts. Academy of management review, v. 22, n. 4, p. 853-886, 1997.

NEUMANN, J V.; MORGENSTERN, O. Theory of Games and Economic Behavior. Princeton: Princeton University Press, 1953.

PHILLIPS, R. A. Stakeholder theory and a principle of fairness. Business Ethics Quarterly, v. 7, n. 1, p. 51-66, 2007.

ROCHA, D. A. Igreja Mundial do Poder de Deus: práticas religiosas para soluções imediatas. 2014, 101 f. Dissertação (Mestrado em História), Faculdade de História, Universidade Federal de Goiás, Goiânia, 2014.

RONCARI, L. No princípio era a imagem. Tempo e Presença, n. 194, p. 25-42, Outubro/Novembro de 1.994.

SMITH, D. A.; CAMPOS, L S. Concentrations of Faith: Mega Churches in Brazil. A Moving Faith: Mega Churches Go South, p. 169, 2014. 
SOUZA, B. 20 coisas surpreendentes sobre o templo da Igreja Universal. Exame.com, São Paulo, 2014. Disponível em: $<$ http://exame.abril.com.br/brasil/noticias/20-coisassobre-o-enorme-novo-templo-da-igreja-universal>. Acesso em: 12 jul. 2015.

THROUP, M.O. O Templo de Salomão em São Paulo? Sobre a ressignificação de símbolos veterotestamentários no movimento neopentecostal o DOI: http://dx. doi. org/10.15603/2176-3828/caminhando, v. 16, n. 1, p. 115-123. Caminhando (online), v. 16, n. 1, p. $115-123,2011$.

Recebido em: 30/07/2015

Aceito em: 16/11/2015

Publicado em: 31/12/2016 